\title{
LA QUINTRALA Y BARRABÁS: FIGURAS DEL EXCESO EN LA PLUMA DE GERONIMO DE UGAS. UNA LECTURA A PARTIR DEL JUICIO DE RESIDENCIA DEL GOBERNADOR MENESES (1670)
}

\author{
LA QUINTRALA AND BARRABÁS: FIGURES OF EXCESS IN \\ THE WORK OF GERONIMO DE UGAS: \\ AN INTERPRETATION OF GOVERNOR MENESES'S TRIAL \\ OF RESIDENCE (1670)
}

Bernardita Eltit Concha

Pontificia Universidad Católica de Valparaíso

Chile

beltit@gmail.com

\begin{abstract}
Resumen: En este artículo propongo que tanto la figura de Francisco de Meneses, denominado comúnmente Barrabás, como Catalina de los Ríos Lisperguer, la famosa Quintrala, pueden ser leídas a partir de la clave del exceso, ya que el gobernador no hace más que llevar al límite las posibilidades del mal gobierno y la encomendera parece ser una muestra ejemplar de la impunidad de la que gozaron los miembros de las familias poderosas del siglo XVII. Ambos personajes son síntomas de la corrupción del ejercicio del poder local, sobre todo cuando logramos ponerlos en relación. Su alianza se erige en polo actancial antagónico a la persecución de la justicia en el texto construido como el cargo $\mathrm{N}^{\circ} 133$ del juicio de residencia de Meneses, narrado por el escribano Geronimo de Ugas a partir de dos juicios que se levantaron en contra de Catalina de los Ríos en la década de 1660 . Ugas se convierte en un verdadero narrador, testigo y personaje de esta obra, si advertimos el carácter eminentemente ficcional del mismo (señalado por Smietniansky para este tipo de informe). Además, encarna la función de escribano en tanto autoridad textual y testigo de lo real, posibilitando la emergencia enunciativa de otras voces, tales como las de las personas que por salvarse a sí y a los suyos huyeron de la encomienda de la Ligua buscando justicia y la voz de la propia Catalina de los Ríos, consiguiendo torcer la mano de la justicia a su favor. Pese a que el texto posee un carácter eminentemente fragmentario y formulaico, nos permite acceder de manera indirecta a estos juicios inéditos y a las configuraciones narrativas que portan en torno a una de las historias de vida más revisitadas de la historia de Chile.
\end{abstract}

Palabras clave: Francisco Meneses (Barrabás), Catalina de los Ríos (Quintrala), exceso, juicio de residencia, escribano, causas judiciales coloniales. 


\begin{abstract}
In this article, I suggest that both Francisco de Meneses, commonly referred to as Barrabás, and Catalina de los Ríos Lisperguer, the famous Quintrala, can be interpreted as figures of excess. While the former, as governor, drove the possibilities of poor governance to its limits, the latter provides a quintessential example of the impunity that members of powerful families enjoyed in the $17^{\text {th }}$ century. Both characters are symptoms of the corruption of local power, particularly evident when we analyze their relationship. Their alliance can be erected on an actantial pole which opposes the judicial persecution expressed in allegation No. 133 of Meneses's trial of residency. This text, narrated by the scribe Geronimo de Ugas, is based on two trials against Catalina de los Ríos in the decade of 166o. In this work, Ugas becomes a true narrator, witness, and character, if we consider the eminently fictional nature of the text, as Smietniansky has observed in these kinds of reports. He also personifies the scribe's function as both textual authority and witness of reality, allowing other voices to emerge, such as those of the people who, in order to save themselves and their families, escaped the Ligua encomienda estate, as well as the voice of Catalina de los Ríos herself, succeeding in his efforts to manipulate the trial in her favor. Although the text is quite fragmentary and formulaic, it allows us to indirectly access these unprecedented trials and their narrative configurations in regards to one of the most revisited life stories in Chilean history.
\end{abstract}

Keywords: Francisco Meneses (Barrabás), Catalina de los Ríos (Quintrala), excess, trial of residency, scribe, colonial judicial case.

Recibido: 29/02/2020. Aceptado: 10/06/2021.

Bárbaro, violento, devoto e inmoral, hecho de pasiones desatadas, atropellos y crímenes, el siglo decimoséptimo ha sido simbolizado en la historia del coloniaje por dos figuras típicas que lo representan, según aseguran, a la perfección; una es el gobernador Meneses, llamado Barrabás; la otra, doña Catalina de los Ríos, la Quintrala, que está, como se sabe, colgada de un cabello a la puerta del infierno.

(Alone. Historia personal de la literatura chilena)

E ntre las huellas documentales más notables que se conservan acerca de los crímenes cometidos por Catalina de los Ríos Lisperguer, La Quintrala, en el siglo XVII, están las que se conservan en el juicio de residencia del gobernador Francisco de Meneses. Estas, junto a las causas judiciales que levantó en su contra el sexto obispo de Santiago, Francisco de Salcedo ${ }^{1}$,

${ }^{1}$ El estudio pormenorizado de dichas causas se encuentra en mi investigación doctoral "Fábulas judiciales. Origen y actualizaciones de la biografía criminal del ícono cultural Quintrala (siglos XVII y XIX)”, 2017. 
forman parte del conjunto de textos que origina la narración de la biografía criminal de este ícono cultural² ${ }^{2}$, quizás uno de los más célebres del periodo colonial chileno. Pese a la relevancia del personaje histórico y la profusa actualización de su vida, el rescate y análisis de estas primeras versiones acerca de los crímenes que cometió continúa siendo una tarea pendiente de la crítica especializada ${ }^{3}$.

El juicio de Residencia de Francisco de Meneses ${ }^{4}$ fue construido entre 1666 y 1676, e informa los 242 cargos que se le presentaron al Gobernador de Chile. Algunos de ellos fueron: malos tratamientos a los soldados y llamarlos mestizos, mulatos y cuarterones; hacer negocios con las enco-

${ }^{2}$ Tomo aquí prestado el concepto de ícono cultural desarrollado por Rolena Adorno (1996). Me parece pertinente al caso de Catalina de los Ríos Lisperguer en tanto constituye una imagen sintética, originada "a partir de un caso histórico y que satisface[n] una necesidad primeramente social de definir, explicar, interpretar y proponer los modos ideales de comportamiento en una edad dada" (906). Sus actualizaciones son relatos de un personaje histórico convertido en emblema fundacional de la cultura latinoamericana, por lo que estos íconos reconstruyen un supuesto origen cultural. Para ver un ejemplo de análisis en torno a otro ícono cultural de la época colonial chilena y sus actualizaciones literarias $c f$. el artículo que publiqué en coautoría con Ximena Azúa Ríos "Corregidor Zañartu. Autoritarismo y Linaje". Revista de Estudios Filológicos, Facultad de Filosofía y Humanidades de la Universidad Austral de Chile. Versión impresa ISSN 0071-1713. Valdivia Chile, junio 2012, pp. 7-23.

${ }^{3} \mathrm{Si}$ bien existen publicaciones en que se analizan fragmentos de las causas judiciales que se abrieron en contra de Catalina de los Ríos Lisperguer, tales como Precursores de la independencia de Chile (1871) y El terremoto de 13 de mayo de 1647 (1882) de Miguel Luis Amunátegui, los estudios de Crescente Errázuriz (1875), Historia Jeneral de Chile (1884) de Diego Barros Arana, Historia de los agustinos en Chile de Víctor Maturana (1904) y Las encomiendas indíjenas en Chile de Amunátegui Solar (1910), destacando entre ellos Los Lisperguer y la Quintrala publicado por Benjamín Vicuña Mackenna en 1877, la crítica contemporánea ha desestimado en general el valor de dicha documentación al momento de construir la historia de las fijaciones escritas de este ícono cultural instalando como inaugural la publicación de V. Mackenna. Cf. Rosa Sarabia (2000), Natalia Cisternas (2001), Alfredo Jocelyn Holt (2001), Olga Grau (2002), Lucía Guerra (2002), Alejandra Bottinelli (2008) y Sandra Garabano (2009).

${ }^{4}$ Archivo General de Indias. Escribanía de Cámara 937, A, B y C y 938 A, B y C. Residencia de Francisco de Meneses, gobernador, capitán general y Presidente de la Audiencia de Chile, por Lope Antonio de Munibe, oidor de la Audiencia de Lima. Fenecida en 1676. Este documento fue hallado, analizado y compartido al equipo por la investigadora Alejandra Araya en el contexto de su proyecto Fondecyt $\mathrm{N}^{\mathrm{O}} 1080096$ "Para un imaginario socio político colonial: castas y plebe en Chile (1650-1800)", (2008-2010) en el que participé como ayudante de investigación y tesista. Vale la pena destacar que el único trabajo especializado acerca del mismo corresponde al capítulo del libro Formas de control y disciplinamiento. Chile, América y Europa siglo XVI-XIX (2014) que la historiadora publicó denominado "Azotar. El cuerpo, prácticas de dominio colonial e imaginarios del reino a la república de Chile". 
miendas; faltar el cuidado a los religiosos; violar correspondencia privada y espiar a los oidores; casarse, falsificando para ello una cédula real; insultar a todo tipo de autoridades; organizar malocas en tierras de paz y bailar con mujeres de todos los estados, entre tantos otros. En la primera pieza del legajo, fechada el 18 de julio de 1676, que corresponde a las sentencias que el Consejo de Indias dictó a partir de la visita, aparece un cargo $\left(\mathrm{N}^{\circ} 133\right.$, condenado en 10.500 pesos en escritura lateral), en el que se afirma que Francisco de Meneses, sobornado por Catalina de los Ríos, la dejó en libertad y levantó el embargo de sus bienes. Penas que estaba cumpliendo por una causa que la justicia le seguía por muertes y malos tratamientos a los indios de su servicio, que, según consigna el escribano, habría tenido más de 2.200 fojas escritas.

En este artículo propongo que tanto la figura de Francisco de Meneses, denominado comúnmente Barrabás, como Catalina de los Ríos Lisperguer, la famosa Quintrala, pueden ser leídas a partir de la clave del exceso. El gobernador no hace más que llevar al límite las posibilidades del mal gobierno y la encomendera parece ser una muestra ejemplar de la impunidad de la que gozaron los miembros de las familias poderosas del período. Ambos personajes parecen erigirse en síntomas de la corrupción del sistema, sobre todo cuando logramos ponerlos en relación. Su alianza se erige en polo actancial antagónico a la persecución de la justicia en el texto construido como el cargo $\mathrm{N}^{\circ} 133$ del juicio de residencia de Meneses, narrado por el escribano Geronimo de Ugas a partir de dos juicios que se levantaron en contra de Catalina de los Ríos en la década de 1660. Ugas se convierte en un verdadero narrador, testigo y personaje de esta obra, si advertimos el carácter eminentemente ficcional del mismo (señalado por Smietniansky para este tipo de informe) ${ }^{5}$. Encarna, además, la función de escribano en

\footnotetext{
${ }^{5}$ Este carácter eminentemente narrativo de la documentación judicial en general, ha sido advertido y estudiado en las últimas décadas por el movimiento Derecho y literatura. Sugiero la compilación de Jorge Roggero, Derecho y literatura. textos y contextos como una buena entrada a esta propuesta de vinculación entre ambas disciplinas (de la que este artículo es indirectamente depositario) ya que incluye artículos claves traducidos al español de autores tan relevantes como James Boyd White, Richard Posner y Robin West entre otros/as. He desarrollado mi propuesta de lectura de las causas judiciales coloniales como textos literarios en "Fábulas judiciales. Cruces para una propuesta metodológica". Joaquín Trujillo y Emilia Jocelyn-Holt (eds.) Ficciones jurídicas. Derecho y literatura en Chile. Santiago: Rubicón, 2019, pp. 103-128.
} 
tanto autoridad textual y testigo de lo real y, a su vez, es el posibilitador de la emergencia enunciativa de otras voces que consignarán pasajes que les configuran también en su calidad de testigos de su propia vida, tales como los de las personas que por salvarse a sí y a los suyos huyeron de la encomienda de la Ligua buscando justicia, y la voz de la propia Catalina de los Ríos, consiguiendo torcer la mano de la justicia a su favor. Pese a que el texto posee un carácter eminentemente fragmentario y formulaico, nos permite acceder de manera indirecta a estos juicios inéditos y a las configuraciones narrativas que portan en torno a una de las historias de vida más revisitadas de la historia de Chile.

Para entender el contexto en el que emerge la figura de Catalina de los Ríos en el juicio de residencia de Francisco de Meneses, vale la pena analizar, aunque sea brevemente, tanto las figuras del gobernador de Chile y Catalina de los Ríos Lisperguer a partir de la clave del exceso, como el género específico que actualiza dicho tipo de informe y la relevancia que tenía en el contexto de la sociedad colonial.

\section{El Gobernador Francisco de Meneses, figura del exceso}

En la Historia Jeneral de Chile (1885), Diego Barros Arana sostiene que el comportamiento del gobernador Meneses y su mal gobierno son un síntoma del relajo moral de la corte española del período. Es importante destacar que, pese a que el comportamiento de Meneses es constantemente criticado por Barros Arana, sostiene que este tipo de prácticas eran propias de hombres que ostentaban cargos de poder en dicho período. Agrega, sin embargo, que "jamas el peculado se habia ejercido con tanto descaro ni habia tomado tan vastas proporciones" $(65)^{6}$. Más adelante, a propósito del actuar de su ejército personal, el historiador afirma: "Aunque la soldadesca habia cometido casi siempre en Chile delitos de ese órden, (...) jamas la desmoralizacion habia tomado formas tan ultrajantes y descaradas, como tampoco nunca habia sido mayor i mas segura la impunidad de los culpables" (71-2). Me parece que este es un aspecto fundamental, ya que estamos

\footnotetext{
${ }^{6}$ Nota aclaratoria: Todas las referencias textuales de este artículo respetan la ortografía que presentan en los textos de los que son extraídas, incluyendo los documentos de archivo.
} 
frente a la construcción de un personaje que, al igual que la Quintrala, no se constituye en clave de excepción sino más bien en la del exceso. Esto porque su actuar más que apartarse del ejercicio de malas prácticas comunes a gobernadores y encomenderos del período, las visibiliza instalándolas en el terreno de lo público. Por lo tanto, es la desfachatez, el descaro, lo que Barros Arana critica en el actuar del gobernador del reino de Chile?

En el quinto tomo de su célebre publicación, específicamente en los capítulos décimo sexto al décimo octavo, el historiador se detiene en la biografía de Meneses. Describe su nombramiento, los servicios de Meneses al ejército español y su participación, como militar de caballería, en Milán, Flandes, Portugal y Cataluña. Sin embargo, afirma que

en cada espedicion i en cada campamento habia cometido actos de desobediencia a sus superiores, o habia tenido querellas, riñas i duelos con muchos de sus camaradas. (...) Este jenio inquieto i turbulento, su inclinación a las discordias i pendencias, i la irregularidad de su conducta, le granjearon desde jóven el sobrenombre de Barrabas (40).

Su viaje y llegada a América no estuvo exento de constantes pleitos y riñas y lo más notable parece ser que el Gobernador se negó a desembar-

\footnotetext{
${ }^{7}$ Algunos ejemplos destacados por Barros Arana son cómo se apropió tanto del sello real, sin el cual la Real Audiencia no podía validar sus resoluciones, como del estandarte real, para evitar un alzamiento en su contra a nombre del Rey (para la importancia del sello real, $c f$. Alfonso X 1576 título xx ley 1 y del sello real y del estandarte $c f$. "los 'fetiches del poder'. Jaime Valenzuela. Las liturgias del poder (2013). De este modo, Meneses ejercía un control absoluto en lo concerniente a las representaciones del poder del Rey en reino. Además, influía en las elecciones de los superiores de las congregaciones religiosas y tenía un sistema para evitar las comunicaciones con la corona, ya que interceptaba cartas que denunciaban su mal gobierno a la par que mandaba a escribir otras, varias formadas a la fuerza, en las que se alababa su gestión. El historiador se detiene, asimismo, en las campañas de Francisco de Meneses, la primera vinculada a la repoblación de fuertes, la segunda, para hacer frente a una insurrección de indios en Purén y la tercera para fundar el fuerte de Virquén (o Repocura), que fue asaltado poco después y los sesenta soldados que estaban bajo el mando del Capitán Paredes resultaron degollados. También narra el intento de asesinato del gobernador por manos de Manuel de Mendoza (quien había sido destituido de su cargo de veedor general del ejército) cuando éste se encontraba en el hospital San Juan de Dios. El intento fallido terminó con Mendoza vestido de loco paseado por la ciudad sobre una mula y finalmente asesinado en la plaza pública, y con Meneses excomulgado, ya que el hospital al igual que los conventos era un lugar de asilo que las autoridades no podían violar, por lo que se opusieron al encarcelamiento y a la sentencia del Gobernador.
} 
car en Buenos Aires ${ }^{8}$. Su llegada a Chile estuvo también definida por la ostentación de una conducta heterodoxa, que fue denunciada en variadas oportunidades a las autoridades, y que iba desde su gusto por los caballos, las mujeres y las fiestas, hasta la burla explícita del Rey de España. En abril de 1664 se casó de manera secreta con Catalina Bravo de Saravia, lo que contravenía la legislación vigente que impedía los matrimonios entre funcionarios reales y miembros de las comunidades que gobernaban. Barros Arana releva, asimismo, la pendencia que mantuvieron el gobernador Meneses y el obispo de Santiago, Diego de Humanzoro. Ésta llevó a Meneses a acusar al Obispo de las más diversas faltas (exigiendo su extrañamiento del cargo) y a este último a escribirle al Rey de España denunciando el mal gobierno de Meneses y su matrimonio clandestino con la hija del Corregidor de Santiago ${ }^{9}$.

La biografía de Catalina de los Ríos Lisperguer parece ostentar ciertos rasgos comunes a los destacados a propósito de la vida del gobernador $\mathrm{Me}$ neses. No me detendré aquí en la narración detallada de su biografía criminal, que por su extensión resulta ser una tarea imposible en este contexto, sino sólo en cómo esta ha sido conceptualizada en su totalidad (y, más adelante, a los juicios que se le siguieron en la década de 1660) ${ }^{10}$.

\section{Exceso, ejemplo o excepción: el caso de la Quintrala}

En Precursores de la independencia de Chile (1871) Miguel Luis Amunátegui considera a Catalina de los Ríos Lisperguer como un ejemplo esclarecedor de los malos tratamientos que recibían los indios domésticos por parte

\footnotetext{
${ }^{8}$ Este episodio fue relatado por Pedro Lozano en el tercer tomo de su libro Conquista del Paraguay, Río de la Plata y Tucumán (1874), a propósito del gobierno de José Martínez de Salazar. Según Lozano, Meneses (a quien también denomina Barrabás) intentó "alzarse en este puerto de Buenos Aires con dos navíos, y pasarse con ellos á Chile por el Estrecho de Magallanes (...) pero le obligó Salazar con mucho valor á ponerse en razón. A otros escándalos se quería arrojar aquel sujeto desbaratado y á todo se le opuso intrépido el presidente" (446-7).

9 Para revisar un análisis del enfrentamiento de Humanzoro con las autoridades del período. Cf. Albornoz, 2010.

${ }^{10}$ Refiero al famoso folletín, o más bien episodio biográfico, publicado por Benjamín Vicuña Mackenna en El Ferrocarril en 1877, publicado más tarde como Los Lisperguer y la Quintrala.
} 
de los españoles en general y de los encomenderos en particular: "Lo que sucedía en la estancia de Catalina de los Rios no era un caso especiálisimo, sino bastante común en todo el reino" (Tomo II, 361). Esta primera aparición de la figura de Catalina de los Ríos en la producción narrativa de corte historiográfico de fines del siglo XIX, aunque breve, no deja de ser significativa, porque lejos de ser conceptualizada por Amunátegui como una excepción (por lo menos en lo referido a los malos tratamientos a los indios de su encomienda), está caracterizada como un ejemplo del actuar de sus contemporáneos. Once años después, escribe el capítulo "Doña Catalina de los Rios de Campofrio Carvajal" en el marco de su libro El terremoto del 13 de mayo de 1647 (1882), y presenta al personaje básicamente como un síntoma de la decadencia de la sociedad colonial de la primera mitad del siglo XVII, como reza el epígrafe de este artículo.

Pese a que Benjamín Vicuña Mackenna en Los Lisperguer y la Quintrala (1877) sostiene que la condición sexo-genérica y la ascendencia "india chilena" de la Quintrala (enfatizada como herencia femenina), serían los elementos centrales que explicarían su tendencia al crimen y a la maldad, no deja de analizar, a propósito de la impunidad que gozó (por el intento de asesinato de su padre), el tipo de corrupción general que había entonces, vinculada sobre todo a los enlaces matrimoniales por conveniencia y a las redes de las familias poderosas y ricas (al igual que lo hiciera el obispo Francisco de Salcedo en el siglo XVII). El autor vuelve a este punto a propósito del intento de asesinato del cura Banegas, donde nuevamente las influencias familiares de Catalina la habrían salvado de pagar su deuda a la justicia. Por lo que podríamos afirmar que el autor reconoce un contexto favorable para que los miembros de la élite incumplieran las leyes y gozaran de impunidad.

En el cuarto tomo de su Historia Jeneral de Chile (1884), Diego Barros Arana vuelve sobre los asuntos de nuestro interés afirmando que

los otros crimenes perpetrados por esa familia [los Lisperguer], crímenes horribles i que dejan ver una espantosa depravacion, fueron igualmente disimulados por la justicia; i la historia social que en nuestros dias los ha sacado a la luz [por Vicuña Mackenna], prueba con ellos la corrupción de las costumbres de esa época, hasta donde había llegado la impureza de aquellos majistrados, i el poder de las familias acaudaladas para vivir seguras en la mas escandalosa impunidad (236). 
El autor sostiene que más que ser un hecho excepcional, este tipo de arreglos entre el poder judicial y las familias poderosas era una práctica común, así como Miguel Luis Amunátegui afirma lo mismo respecto de los malos tratamientos a los indios de encomienda. En este sentido, para el autor, el actuar de la Quintrala y su familia, más que representar excepciones al comportamiento de las castas dominantes de la época colonial, corresponderían al accionar corriente de las mismas en dicho período.

Por su parte, Domingo Amunátegui Solar en su libro acerca de las encomiendas indígenas en Chile (1910) se hace cargo de analizar algunos de los crímenes atribuidos a Catalina de los Ríos Lisperguer, como revisaremos más adelante. Básicamente sostiene que la Quintrala sufre de sadismo y que, al estar enferma, no es responsable por los crímenes cometidos. Sin embargo, en el contexto más general del libro, ella funciona como una muestra ejemplar de lo que significó el sistema de encomiendas, que el autor critica duramente. Amunátegui se pregunta por qué la justicia no intervino en algunos de los crímenes perpetrados. La respuesta se relaciona con los vínculos familiares de Catalina y al hecho de que tenía el favor de la orden de San Agustín. Todos los cuales, según el autor, la pretendían heredar: "Los delitos, sin embargo, fueron acumulándose unos a otros, i llegaron a formar montaña. Las olas empujaron a las olas, i su rumoroso estruendo se oyó en la capital" (146).

En suma, si Catalina de los Ríos más que una excepción a los comportamientos de las clases dominantes del período es un buen ejemplo del actuar de las mismas, como sostienen Amunátegui, V. Mackenna, Barros Arana y Amunátegui Solar ${ }^{11}$, ¿por qué es ella quien ha sobrevivido en el imaginario chileno y en las historias que nos contamos como la maltratadora, la azotadora de esclavos, la asesina?; “por qué [Vicuña Mackenna] trata el caso de doña Catalina como atrozmente excepcional, como una instancia monstruosa, cuando en la colonia era usual la incidencia de la perversión” (Guerra 200253$)^{12}$. Lucía Guerra sostiene al respecto que durante la colo-

\footnotetext{
${ }^{11}$ Existe, de todos modos, una lectura minoritaria que difiere de lo sostenido por estos autores, que señala que el caso de la Quintrala es una anomalía de la sociedad colonial del siglo XVII y no una metáfora de dicho período. Cf. Eyzaguirre.

${ }^{12}$ Araya (2014) sostiene que en los extractos de los juicios aparecen elementos vinculados al exceso no tanto por la crueldad de la existencia del castigo de azotes sino por la falta de racionalidad en su aplicación.
} 
nia e incluso en los siglos posteriores estás prácticas son realizadas usualmente por varones, por lo que "la sensación de horror de Vicuña Mackenna proviene, más que nada, del hecho de que la Quintrala fuera mujer" (53). Guerra afirma que, a través de una retórica del mal, el autor modeliza el exceso contraviniendo la deseada norma de la sobriedad del carácter nacional, caracterizado como apolíneo y apegado a las leyes. Además, puntualiza la homologación que realiza Vicuña Mackenna entre la Quintrala y el sujeto mapuche (dada su ascendencia) a quien era necesario marginar en el proceso de construcción del estado nacional.

Es importante destacar que para Lucía Guerra "todo aquello que desborda o excede ‘lo apolíneo' -generalmente llamado las 'normas del buen gusto y la educación'- se hayan atribuido siempre a un otro perteneciente a los grupos marginalizados" (55). Si bien esta regla puede aplicarse a Catalina de los Ríos, en tanto mujer, no funciona en el caso de Francisco de Meneses, español y rico gobernador del reino.

De todos modos, ambas figuras encarnan el desafío al carácter nacional ‘apolíneo' analizado por Guerra desde la posición de privilegios que gozan en su condición de Gobernador, Meneses y encomendera, la Quintrala. Interesante es destacar que dichos privilegios funcionan justamente en la medida en que este tipo de personajes son vistos como pertenecientes a una misma red de influencias que maneja el poder político, económico y judicial. En ese sentido, el juicio de residencia, como género narrativo, permite analizar justamente cómo este entramado de relaciones opera y se consolida en la conformación de un poder local que muchas veces desafía de facto el poder de la corona en Indias.

\section{El juicio de residencia, entre la escenificación del poder real y el ejercicio de poder local}

Me gustaría introducir, en este punto, algunas consideraciones básicas acerca del sentido de este tipo de informe y la relevancia que les atribuyó la corona española en el contexto de la administración de sus colonias hispanoamericanas. Las visitas o residencias fueron oficios claves para mantener el control de las autoridades indianas, y, al mismo tiempo, constituyeron un espacio de poder en el cual se negociaron intereses particulares. Fueron 
armas de doble filo que por una parte ritualizaron, siguiendo el término de Smietniansky (2007), el poder de la corona en sus colonias, pero que por otra parte supusieron una forma de control local de los vecinos sobre las autoridades españolas designadas para gobernarlos. En este sentido, los juicios de residencia constituyen hoy un valioso registro que permite leer campos de tensión entre poderes enfrentados y alianzas estratégicas, más que entre la corona y sus autoridades, entre los diversos intereses de las oligarquías locales ${ }^{13}$.

El juicio de residencia ponía en escena especialmente a la élite local pues era el sector privilegiado, encargado de la administración política de las ciudades y, por tanto, el que estaba siendo examinado pero también eran sus miembros los que actuaban como testigos, jueces y escribanos. Estos últimos eran fundamentales, como responsables de escribir y certificar lo que iba sucediendo a lo largo del proceso" (Smietniansky 2007: 74-75).

Juan Solórzano Pereira, el destacado jurista, en 1648 publicó en su Política indiana algunas reflexiones en torno a la práctica de las residencias. El autor afirma que

no solo se procede a la averiguacion, i pesquisa de las acciones de los Presidentes, Oidores, i demas Ministros de las Audiencias de las Indias, i otros que en ellas huvieren tenido cargos de administracion de justicia, ò hazienda Real, en la forma, q se ha dicho en los capítulos passados; pero tabien, quado por cualquier modo dexa, ò acaba los oficios ò passan

\footnotetext{
${ }^{13}$ En cuanto a los aspectos procedimentales de los juicios de residencia, hay que relevar que el primer paso para su realización es que el juez residenciador designado para tal efecto jura ante el cabildo su cargo, una vez finalizado el período del funcionario al que va a juzgar. Luego comienza el juicio indagatorio, en el que se publican edictos pregonados que tenían el objetivo de hacer llegar al juez las quejas que existieran en contra del funcionario (por daños personales o de bienes u honra). En tercer lugar, el juez designa a sus colaboradores, empezando por el escribano de la residencia y los comisionados que levantarán sumarios en distintos lugares. Luego se precisan las personas subalternas al residenciado ya que sus gestiones se incluyen en el juicio. De esta forma en este primer período procesal el juez investiga por todos los medios posibles al residenciado (incluyendo declaraciones de testigos). La segunda etapa se vincula con la formulación de cargos. En caso de ser hallado culpable el juez debía proponer una pena (multas, traslados, destierros e inhabilitaciones temporales o perpetuas eran comunes), y finalmente el proceso pasa a la autoridad superior, quien sentencia. En el caso de los gobernadores quien lo hace es el Consejo de Indias (cf. Martínez Baeza 1999).
} 
a otros mayores, estàn obligados al Sindicado, i residecia dellos, como cualesquier otros Corregidores, i Magistrados temporales. Porque con este freno se ha juzgado estaràn mas atentos, i ajustados à cumplir sus obligaciones, i se moderaràn en los excessos i insolencias, que en provincias tan remotas puede, i suele ocasionar la mano poderosa de los que se hallan tan lexos de la Real (836-7).

Solórzano advierte a los jueces visitadores que no crean todas las acusaciones que se les hacen a los residenciados ya que se han usado también contra hombres inocentes. $\mathrm{O}$, dicho de otro modo, que entorpecen la ejecución de la justicia ya que las autoridades temen ser rechazadas por los vecinos, y por consiguiente visitados: "i se lo oi dezir al Marques de Montesclaros Virrey del Perù que comparaba estas visitas à los torvellinos, que suele aver en placas i calles, que no sirven sino de levantar el polvo, $i$ paja, i otras horruras, de ellas, i hazer que se suban à las cabezas" (840). De este modo, podemos advertir el carácter de las visitas y la relevancia que ostentaron en lo que dice relación con el establecimiento y permanencia de las autoridades y, por ende, en la configuración de las élites locales y mantención de sus privilegios en base a una precaria red de vínculos familiares, alianzas y favores, como revisaremos de manera específica en el cargo 133 del juicio de residencia del gobernador Meneses.

\section{Antecedentes: alusiones a los juicios levantados en contra de Ca- talina de los Ríos en la década de 1660}

La mejor referencia a los procesos levantados en contra de Catalina de los Ríos Lisperguer en este período es la que incluye Domingo Amunategui Solar en su libro Las encomiendas de indíjenas en Chile (1910). De hecho, anexa a su publicación un extenso documento denominado "Esposicion del oidor Huerta Gutiérrez en 1660" tomado del archivo particular de don José Toribio Medina (como reza la bajada de título). A partir de éste (y de las investigaciones de Miguel Luis Amunátegui ${ }^{14}$, Benjamín Vicuña Mackenna

${ }^{14}$ Miguel Luis Amunátegui (1871) transcribe el fragmento de un acuerdo del 17 de enero de 1660, citado del Libro de votos de la Audiencia de Santiago de Chile, en que se acordó que Francisco Millán, receptor de la Audiencia, fuera a la Ligua, a la Estancia de doña Cata- 
y Víctor Maturana) refiere los castigos, torturas y asesinatos que practicaba con las personas de su servicio doméstico, los que habrían sido comprobados en el proceso que inició la Real Audiencia a este respecto.

El autor relata cómo el 17 de enero de 1660, a propósito de un azote general de la Quintrala sobre sus indias en una siembra de maíz, se reunió la Real Audiencia y decidió enviar al receptor Francisco Millán para que averiguara en la Ligua lo que estaba sucediendo. Considerando lo constatado por el receptor, decidieron enviar, el 18 de abril, a Juan de la Huerta Gutiérrez para que tramitara el proceso y lo sentenciara en primera instancia. He aquí el origen del informe publicado por Amunátegui Solar en este libro en el que se constatan 39 asesinatos. El autor sostiene que en este tiempo cambiaron todos los oidores de la Real Audiencia y Catalina apeló su sentencia valiéndose del indulto que otorgó Felipe IV con motivo del nacimiento del príncipe heredero en 1663.

Amunátegui continúa su narración relatando cómo un año más tarde, cuando vivía en su chacra de Tobalaba, Catalina de los Ríos asesinó a Micaela, esclava de Francisco de Figueroa ${ }^{15}$. La Real Audiencia comisionó a Juan de la Peña Salazar para que levantara la información del caso, lo que culminó con un juicio iniciado el 18 de julio y se ordenó la prisión de Catalina. Sin embargo, en este caso intervino el Gobernador del reino Francisco de Meneses, quien el 13 de diciembre pronunció un auto para que se desembargaran sus bienes "i se entendiera la prision dentro de cuatro leguas de contorno de la ciudad de Santiago" (cit. en Amunátegui Solar, 1910: 157). Amunátegui Solar alude también al cargo $\mathrm{N}^{\circ} 133$ del Juicio de Residencia del Gobernador Meneses, en el que se le acusa de haber recibido 8 oo quintales de sebo por su intervención en este caso, además de siete mil cabras y una cadena de oro. Finalmente, concluye Amunátegui, después de la muerte de Catalina de los Ríos en 1665 y terminado el período de gobernación de Meneses el 24 de diciembre de 1668, los oidores dieron senten-

lina, a averiguar de manera secreta si eran ciertos los excesos cometidos por Asencio Erazo, según 'corría la voz' en ese entonces.

${ }^{15}$ He realizado un extenso análisis de dicho juicio, conservado en el Archivo Histórico Nacional, en mi tesis doctoral "Fábulas judiciales. Origen y actualizaciones de la biografía criminal del ícono cultural Quintrala (siglos XVII y XIX)”. Además, Benjamín Vicuña Mackenna se ocupa de revisarlo detalladamente en su texto "El último de los cuarenta asesinatos de Doña Catalina de los Ríos”. Revista de Artes y Letras I. (1884): 46-70. 
cia, confirmando las penas impuesta por Ramirez de Laguna en 1661.

Benjamín Vicuña Mackenna (1877) ya había referido estos hechos y los procesos que se abrieron a partir de ellos. De hecho, numera como el sexto de los crímenes que conforman la biografía criminal de esta mujer, los malos tratamientos a los indios de su encomienda: "i así era la horrible verdad de aquel caso estraño, porque doña Catalina mataba a destajo i por su propia mano a niños, a ancianos, a doncellas, a sus capataces de vacas, a sus mujeres, a sus pastores humildes" $(113)^{16}$.

En el capítulo "El proceso de la Quintrala i su testamento" el autor expone el proceso que se siguió en la Real Audiencia contra Catalina de los Ríos, iniciado en enero de 1660, por la matanza de personas a su servicio. En este contexto se alude a un nuevo crimen, el séptimo en el que Vicuña se detiene, que corresponde al asesinato de Micaela: "esclava ajena i de la servidumbre del capitán Francisco Figueroa, quien salió a la demanda por el alma de la víctima i por el dinero que le costaba, pues era hombre pobre” (125). Finalmente, Vicuña Mackenna releva la relación entre el gobernador Meneses y la Quintrala, ya que él la ayudó a no ser castigada por la justicia en los últimos días de su vida: "Por las demostraciones con que el dicho vuestro presidente don Francisco de Meneses favorece a doña Catalina Flores de los Ríos por los agasajos i dádivas con que lo ha asegurado, que en todo suplico a Vuestra Majestad se sirva de mandar" (Carta del Oidor Peña Salazar, cit. en Vicuña 1877: 127).

En este contexto, resulta de gran interés introducir un análisis del cargo $\mathrm{N}^{\circ} 133$ del juicio de residencia del gobernador Meneses, a través de cuya narración dicho arreglo entre el Gobernador del reino y la rica encomendera quedará explicitado, denunciado y fijado textualmente por primera vez.

${ }^{16} \mathrm{El}$ autor afirma que en el testamento de Catalina se comprueban sus crímenes ya que "por término medio sus albaceas pagaron a razon de cincuenta pesos el rescate de cada cadáver de indio, i por el doble los de esclavos, macho o hembra" (114). Luego de copiar los cinco casos, todos de mujeres, y cuánto se les pagó a sus deudos, Vicuña Mackenna afirma que también hay casos por varones en estos "partidos de composición extrajudicial" ya que se habla de satisfacciones para referirlos. El autor autoriza esta información con los cuadernos originales de Urquiza, el albacea de Catalina de los Ríos, que dice tener a la vista. 


\section{El cargo $\mathrm{N}^{\circ} 133$ del juicio de residencia del Gobernador}

Esta narración corresponde al documento que generó el escribano público del cabildo de Santiago de Chile, Geronimo de Ugas, el 23 de enero de 1670, cinco años después de la muerte de Catalina de los Ríos y dos años antes de la muerte del gobernador Meneses. Ugas dice copiar, básicamente, fragmentos de las causas que se encontraban en el despacho de la secretaría de cámara de la Real Audiencia en ocho cuadernos de distintos tamaños "que parece aber / se fulminado contra d[oñ]a Catalina de los / rrios difunta mujer lex[iti]ma que fue del m[aes]tro / de campo don Alonso de Carvajal campo / frio sobre los castigos y muertes que se dice / en $\mathrm{d}$ [ic] ha causa aber echo la susod[ic] ha a las jentes / y esclavos de su serbio (sic)” (142).

El documento puede ser dividido en seis partes: La primera corresponde al marco textual narrativo en el que Ugas autoriza su práctica (la copia de documentos que efectivamente existen) y en un informe del contenido de los mismos. La segunda, se relaciona con el juicio que se abrió en contra de Catalina de los Ríos en 1660; la tercera se centra en una segunda causa que se le imputa en 1664. La cuarta corresponde a la explicitación del lugar de enunciación y el sentido de la configuración textual, ya que Ugas fecha el 23 de enero de 1670 la entrega de su documento para que conste en la residencia que Munibe lleva contra el gobernador Meneses. La quinta parte del texto incluye una petición formal de Catalina de los Ríos al Gobernador y el auto en el que él se la concede; y la sexta finaliza, al modo de la cuarta, certificando la documentación.

En la primera parte, que se encuentra entre las fojas 142 y 142v, Geronimo de Ugas asegura (en los términos acostumbrados para tal efecto, es decir, da fe) estar en presencia de las causas que se levantaron en contra de Catalina de los Ríos, las que separa en dos. Anuncia que la primera corresponde a una causa criminal sobre castigos y muertes en la gente de su servicio denunciadas por un esclavo llamado Lorenzo Cordobán y algunos indios de su encomienda (de la Ligua), con sentencia pronunciada; y que la segunda parte corresponde a una cabeza de proceso hecha por Juan de la Peña Salazar sobre la muerte de una mulata.

A mí modo de ver, lo más interesante de este fragmento que abre el documento es la presencia de una primera persona narrativa fuerte, que nos permite hablar en propiedad de un narrador que posibilitará la emergencia 
y certificación de lo aseverado: "Yo el capitán Geronimo de Ugas esc[riva] no pu[blico] / De Cabildo y Real deesta muy / Noble y muy leal ciudad de $\mathrm{s}$ [a]n / tiago de chile y su jurisdission / po (sic) el Rey n[ues]tro s[eño]r qual presente asisto al despacho / de la secretaria de cámara deesta r[ea]l audien[ci]a / doy fee verdadero testimonio" (142).

Esto quiere decir que toda la narración descansa en el testimonio de Ugas, en la ficcionalización narrativa de que su copia corresponde en efecto a los contenidos que se encuentran en los cuadernos que se guardan y que contienen las causas que se siguieron en contra de Catalina de los Ríos. De hecho, la primera, la cuarta y la sexta parte del documento corresponden exclusivamente a los marcos de legitimación y coherencia que otorga Ugas al manuscrito completo, lo que cobra sentido al enfatizar el carácter de copia (imitación, falsedad) y no original (verdadero, real) del mismo.

Es importante destacar en este sentido la figura del escribano, conceptualizado por Alfonso el sabio, en el título xix de la tercera de sus Siete partidas (1576), como alguien que debe ser guardado y honrado:

Leales e buenos e entendidos deven ser los escrivanos de la corte del Rey e que sepan bien escrevir de manera que las cartas que ellos fizieren que bien semeje que de corte de Rey salen, e q[ue] las fazen omes de bue[n] ente[n]dimiento (...). Otrosi dezimos, que los escrivanos publicos q[ue] son puestos en las cibdades, $\mathrm{o}$ en las villas, o e[n] otros lugares q[ue] deve ser omes libres, e christianos, de buena fama. E otrosi debe ser sabidores en escrevir bie[n], e entendidos de la arte de la escrivania, de manera que sepa bien tomar las razones, o las posturas q[ue] los omes pusiere[n] entresi ante ellos. E deven ser omes de poridad ${ }^{17}$ de guisa q[ue] los testame[n]tos, e las otras cosas q[ue] les fuere ma[n]dadas escrevir en poridad, q[ue] no las descubran de ninguna manera: fueras en de si fueren a daño del Rey, o del reyno. E demas dezimos que deven ser vezinos de aquellos lugares onde fueren escrivanos, porque conozcan mejor los omes entre quien fizieren las cartas, e deven ser legos, porq[ue] han de fazer cartas de pesquisas, o de otros pleitos, en que cae pena de muerte o delision, lo que non pertenece a clérigo, nin a otros omes de orden, e demas, porque si fisiessen algun yerro por que mereciessen muerte, o alguna pena que se le pueda el rey acaloñar (122-122v).

${ }^{17}$ Poridad. del lat. purı̌tas, -ātis. 1. f. desus. puridad. en poridad. 1. loc. adv. desus. en puridad (II secretamente). 
De este modo, vemos cómo los escribanos deben ser, o por lo menos parecer, personas de respeto y honra, preparadas y discretas que deben cuidar los intereses del rey y de sus súbditos. Su letra, de este modo, está autorizada por el sólo hecho de ostentar el cargo de escribano. Por lo mismo, los escribanos poseen una gran responsabilidad social y con la corona, y de fallar en sus funciones: "Fasedad faziendo escribano de la corte del Rey en carta, o en previlegio debe morir por ello (...) si el escribano de ciudad, o de villa fiziere alguna carta falsa, o fiziere algu[n]a falsedad en juicio en los pleitos q[ue] le mandaren escrevir, deven le cortar la mano con la que fizo e darle por malo de manera q[ue] non pueda ser testigo, ni aver ninguna ho[n]rra mie[n]tra biviere" (126v y 127). Esto quiere decir, sobre todo en el contexto colonial, que el escribano es una representación del poder real y, relacionado íntimamente con lo anterior, que debe honrar el lugar que ocupa como certificador de lo real: "no mudando nin cambia[n]do ninguna cosa de la substancia del fecho assi como en el registro fuere puesto" (124v). De este modo, el escribano se erige en la figura del testigo por antonomasia, ya que lo que él escribe es lo real (en su doble acepción: de regalis, es decir del rey, y de realis, es decir que existe): por otra parte, esta condición permite identificar el texto justamente como un testimonio, uno que ostenta la calidad de real por el lugar que su autor ocupa en la sociedad de entonces (género contemporáneo de relevante importancia en América Latina, que tiene sus orígenes justamente en este tipo de documentación).

La segunda parte del texto se hace cargo de la causa que se abrió en contra de Catalina de los Ríos por malos tratamientos en la gente de su servicio el año 166o. Se divide, a su vez, en cuatro apartados: el auto cabeza de proceso, los testimonios, los exámenes físicos y la sentencia. Quizás el elemento más interesante de esta colección corresponda a los crudos testimonios que se reproducen ${ }^{18}$.

El auto cabeza de proceso está fechado el 15 de abril de 1660. En éste se informa cómo la noche previa se presentó ante el presidente y los oidores

\footnotetext{
${ }^{18}$ A propósito de la discusión en torno a las penas corporales y al lugar que el azote ocupa dentro de ellas en nuestra sociedad a partir del período de la colonización europea en América, Alejandra Araya rescata el juicio de residencia del Gobernador Meneses, especialmente el cargo 133, del que transcribe fragmentos en los cuales indios y esclavos de Catalina de los Ríos dan cuenta de los malos tratamientos a los que son sometidos, para lo cual muestran su cuerpo herido como prueba y constatación, $c f$. Araya 2014.
} 
de la Audiencia el esclavo Lorenzo Cordobán con su esposa Lorenza, india libre, y Pablo, indio, con su hijo Lázaro de trece años, todos de la encomienda de Catalina de los Ríos en La Ligua. Estas cuatro personas habían llegado a Santiago escapando de su ama debido a los malos tratamientos de los que eran víctimas, y solicitaban que el esclavo fuera vendido y que los indios quedaran en libertad. La forma en que este grupo de personas probó los malos tratos a los que eran sometidos fue mostrar ante la Audiencia las profusas heridas de sus cuerpos ${ }^{19}$.

A este auto cabeza de proceso le suceden, entre las fojas 144 y 152, los testimonios de Lorenzo, Pablo y Lorenza (o Lorencilla). Se sigue la fórmula usada entonces en los tres casos, que consta de la fecha, el nombre del testigo, el juramento, la lectura del auto (en este caso de enero de 1660, por el que se había mandado a Francisco Millán a La Ligua y el del presente día, es decir del quince de abril de 1660) y luego comienzan las respuestas del testigo a las preguntas que se formulan. Así empieza el primer testimonio en el que Lorenzo se identifica como esclavo de Catalina de los Ríos, y enumera una larga lista de personas asesinadas y maltratadas por su ama ${ }^{20}$. También menciona a los mayordomos que buscan a los huidos, estos son Ascencio Laso y Rodrigo de Oses, quienes los traen azotados y en prisiones. Además, acusa el exceso de trabajo (ya que trabajan todos,

\footnotetext{
${ }^{19}$ No debe sorprendernos la petición de ser vendido de un esclavo. Carolina González afirma que "los esclavos demandaban para reparar una injusticia cometida por sus amos o para acusar el incumplimiento de alguna disposición testamentaria que garantizaba la carta de libertad o el papel de venta. Estas solicitudes ante los representantes judiciales se fundamentaban, a su vez, en el derecho a petición y el derecho a defensa" (2014: 18). La autora sostiene que las solicitudes judiciales son una forma -gradual pero abundante- de resistencia al sistema esclavista y que los/as esclavos/as demostraron su calidad y honor a través de sus cuerpos, ya que en general, como en este caso, las demandas eran justamente por haber recibido malos tratamientos.

${ }^{20}$ Lorenzo narra cómo asesinó a su segunda esposa, Felipa, y cómo maltrata a su actual esposa Lorenza. Menciona además que cuando Francisco Millán (receptor de la Real Audiencia) fue a la Ligua (a hacer averiguaciones por el rumor que corría acerca de malos tratamientos), Lorenza fue escondida para que no viera el estado en que estaba. Alude al estado deplorable de varias chinitas (aprisionados con cormas, que duermen en el cepo) y dos muchachos Lázaro y Panchilllo, y el indio Juan. Menciona a un sobrino de la propia Catalina que también estaba en el cepo. Alude al asesinato de un cholillo llamado Losillo de ocho años, de una negra llamada Luisa y su madre, María, además de dos mulatas llamadas ambas Juancillas. Lorenzo afirma, además, que Catalina lo obligaba a maltratar a otros, con azotes y palos (se detiene bastante en el caso de una mujer embarazada de ocho meses, $c f$. 146).
} 
también los niños pequeños, en las siembras, curtiembres, matanzas y en el cáñamo, hasta los días domingo, en las fiestas, en las pascuas y en el día de corpus) y la falta de doctrina. Concluye el testimonio nuevamente con las fórmulas que incluyen dejarlo abierto (por si el testigo recuerda más hechos), la consignación de una edad aproximada para el testigo, en este caso de treinta años, la confirmación de la veracidad de lo testificado, en este caso que no obedece al odio a su ama sino al miedo de que lo asesine, la firma (o su ausencia ya que de hecho Lorenzo no firma porque no sabe hacerlo) y se cierra con el "ante my Juan de Agurto es[criba]no pu[blic]o" (148).

El segundo testimonio es el de Pablo, identificado como indio analfabeto de cincuenta años, quien denuncia los malos tratos de su ama con su hijo Lázaro, razón por la cual huyó con él "por que su / ama esta echa a matar de asotes a su / jente" (148v). También denuncia el asesinato de sus sobrinos Losillo y Madal y de su hija Jeromilla entre otras muchas muertes. Menciona, al igual que Lorenzo, el actuar del mayordomo Ascencio y la falta de doctrina. Es de notar que tanto Pablo como Lorenzo habían huido de la encomienda para salvar de la muerte a su hijo y a su esposa, respectivamente.

El tercer y último testimonio corresponde a la india Lorencilla, de dieciséis años, casada con Lorenzo. Explica que ha sido duramente azotada por tratar de escapar de los castigos de su ama, quien no la deja hacer vida marital, además de tenerla con grillos y durmiendo en el cepo, por lo que le pidió a su marido, temiendo por su vida que, en sus palabras, la hurtase: "este testigo esta / en serbissio de la d[ic]ha doña catalina / flores ${ }^{21}$ abra poco mas de dos años y lo que / a bisto en este tiempo es que todas las / criadas las chinas las mulatas / y los muchachos andan asotados / y lastimados y con prisiones" (150v). Denuncia además y de manera específica el asesinato de Losillo de siete años y de Luisa, negrita de la misma edad. En este testimonio aparece una figura masculina denominada "el hombre", que podemos asumir que corresponde a Francisco Millán porque la testigo alude a él como "el que escribe" ( $c f .151)$, y marca un antes y un después en

${ }^{21}$ No debe llamar la atención que los apellidos oscilen, en la documentación de esta época es común. Por ejemplo, se puede leer Alonso Carvajal o Campofrío indistintamente o Catalina Lisperguer o Flores. 
la vida de la encomienda. Recuerda que a ella y a todos los maltratados los escondieron en el monte hasta que el hombre se fue (a excepción de dos mulatas que se quedaron en prisiones). Alude, al igual que Pablo y Lorenzo, a la falta de doctrina y al exceso de trabajo.

Después de los tres testimonios aludidos aparece un apartado anunciado como "Fee de llagas de la yndia", pero en el que también se informa el estado de Lázaro y Lorenzo ( $c f$. 152-153). Estos exámenes físicos son tomados por el escribano Juan de Agurto el 15 de abril de 1660, el mismo día en que está fechado el auto cabeza de proceso. En ellos se constatan las lesiones que muestran los cuerpos examinados, las que dan cuenta de constantes golpes y heridas aún abiertas.

Es importante destacar que Agurto cede la voz a los testigos en lo que podríamos denominar un estilo directo, o indirecto libre, ya que a ratos les presta su voz, o su lugar de enunciación. Esto se vincula con la propuesta de Azúa (1995), que retoma González (2014), y que permite entender que en los testimonios de las causas judiciales aparecen retazos autobiográficos en los que se "cuelan", pese al filtro que supone el escribano, construcciones identitarias subalternas, en este caso las de los/as esclavos/as e indios/as de la encomienda de Catalina de los Ríos.

La voz de Geronimo de Ugas vuelve a aparecer en este punto para afirmar que "despues de aberse echo otras muchas dili / jensias tocantes a la aberiguasion de los / casos contenidos en la cabeza de proceso / a foxas dos mil dussientas y diez y seis de / el proceso parece estar la sentencia de el / thenor siguiente" (153). De este modo, como afirmaba, reaparece la voz de Ugas quien resume los contenidos de la causa (muchas diligencias tocantes a la averiguación de los casos narradas en más de dos mil fojas) para cerrar esta primera parte de su texto, el cargo 133 del juicio de residencia del gobernador Meneses, con la sentencia de esta causa. De este modo, el 18 de junio de 1661, Antonio Ramírez de la Laguna, el juez de la causa, condena a Catalina de los Ríos a pagar a sus indios vestimenta y cabezas de ganado, además de embargar su hacienda y dejarla en prisión. Dicha sentencia se le comunicó a Catalina de los Ríos el 21 de junio del mismo año, de manera presencial y en su casa. Esta causa culmina de la siguiente manera:

y abiendo la d[ic]ha doña cata / lina de los rrios pagado la condenasion / costas y salarios se le alza el embargo / y deposito de sus hasiendas 
y se mandan / entregar y por esta mi sentencia difini / tiba juzgando asi lo pronuncio y mando / con costas y salarios en que condeno a la / susod[ic] ha dotor don Antonio ramires de la / guna (154-154v) $)^{22}$.

De esta forma, termina la segunda parte del cargo 133, que corresponde a la primera causa contra Catalina de los Ríos que Ugas incorpora. Si aquí terminara el documento, quedaría evidencia de la eficiencia de la justicia ya que una encomendera maltratadora habría sido oportunamente castigada (encerrada, embargada y penada en dineros y especies). Sin embargo, como se probará más adelante en el propio documento, y como mostramos al comienzo de este apartado, Catalina no cumplirá con lo establecido en esta sentencia, en parte gracias a los favores del gobernador Meneses.

En la foja $n^{\circ} 55$ del texto se abre lo que, en mi opinión, corresponde a la tercera parte del mismo, ya que comienzan las alusiones a la segunda causa que se le imputa a Catalina de los Ríos, con un auto cabeza de proceso fechado en 18 de julio de 1664. Antes de comenzar el análisis de esta sección de textos, quiero hacer hincapié en el carácter eminentemente fragmentario del documento que analizamos, en la medida en que, como demostré más arriba, es Jerónimo de Ugas quien selecciona los apartados que le parecen más acertados para construir el cargo en contra del gobernador.

En este auto cabeza de proceso, don Juan de la Peña Salazar, oidor de la Real Audiencia de Santiago, afirma haber recibido la noticia de que Catalina de los Ríos Lisperguer había asesinado mediante azotes a una mulata del capitán Francisco de Figueroa, que él mismo le había prestado y quien, al enterarse de lo ocurrido, la habría desenterrado para averiguar la verdad

${ }^{22}$ Un elemento interesante de este auto es que se menciona que debido a los rumores que circulaban, la Audiencia había enviado anteriormente a la Ligua a un receptor, Francisco Millán, para averiguar lo ocurrido (auto del siete de enero de 1660), además de comprometer una segunda visita a cargo de don Juan de la Huerta Gutiérrez. Aunque en la transcripción de Ugas no se encuentran los resultados de dichas visitas, afortunadamente Amunátegui Solar en 1910 va a anexar en su libro Las encomiendas indíjenas de Chile un documento denominado "Esposicion del oidor Huerta Gutiérrez en 1660" (tomado, según el autor, del Archivo particular de José Toribio Medina) en el que se informa que Catalina de los Ríos fue condenada: "Honra en estremo al doctor Huerta Gutierrez este documento firmado por él, en que constan con desnuda verdad los crímenes de doña Catalina de los Ríos, -documento precioso que permite a la historia tramitar i sentenciar de nuevo el juicio, para eterno ludibrio de los oidores que no supieron o no quisieron cumplir con su deber" (151). 
acerca de su muerte (nuevamente el escribano del caso es Juan Agurto).

A diferencia del caso anterior, Ugas de inmediato salta a la sentencia del caso, fechada el día 24 de diciembre de 1668 ( $c f .155 v$ ). En esta se alude al indulto por el nacimiento del rey Carlos y a la propia muerte de la imputada, sin embargo, Gaspar de Cuba y Arce y Luis de la Peña Salazar confirman la sentencia de Antonio Ramírez de la Laguna: "mandamos se alse el embargo / de bienes ara que viede ellos el d[ic]ho / albacea conforme a la dispusision y ul / tima boluntad de la d[ic]ha doña catali / na flores y por esta n[uest]ra sentensia di / finitiba asi lo pronunsiamos y manda / mos" (156v). El que hace este traslado que copia Ugas, es Joseph Álvarez de Toledo, escribano público, el 8 de enero de 1669.

Reaparece por tercera vez en este momento la voz de Ugas, el narrador marco del texto, en lo que podríamos entender como una cuarta parte del cargo, para mencionar por vez primera lo que ya sabemos: que está copiando documentos del despacho de la secretaría de cámara para el señor licenciado López Antonio de Munibe:

oidor de la r[ea]l audienc[ia] de lima y juez / visitador de los procedimientos del señor / D[o]n Fran[cisc]o Menes (sic) presidente / ob[ernado]r y cap[ita]n g[enera]l de / este reyno que a sido y para los efectos que / conbengan doy el presente en la ciu[da]d de / s[a]ntiago de chile en beynte y tres dias de / el mes de hen[er]o de mill y s[eiscient] os y setenta a[ño]s (157v).

La página está firmada por Ugas, y debajo de su signatura aparece un pequeño texto que informa que el 23 de enero de 1670 el escribano entregó estos documentos al juez visitador, lo que certifica Francisco Muñoz, escribano "de su magestad".

Sin embargo, lejos de concluir el documento, aparece aquí un testimonio construido en primera persona por la propia Catalina de los Ríos Lisperguer, quien hace una petición formal al Gobernador, Don Francisco de Meneses. Aquí se abre una quinta parte del cargo, que dada la importancia que posee y pese a su extensión, transcribiré in extenso:

Doña catalina de los rrios viuda de el / $\mathrm{m}$ [aestr]o de campo don Alonso de Carvajal / y campo frio= digo que estandose ful / minando causa criminal contra mi sobre yn / putarme la muerte de Micaela mulata es- 
claba del cap[ita]n don Fransisco de Figueroa que / tenia en mi serbisio y teniéndome presa por / esta causa y embargados mis bienes que tenia / en mi chacra y estando pendiente arti / culo sobre mi soltura y desenbargo de bienes / debaxo de las fianzas de la seguridad de mi / persona y de jusgado y sentenciado que tengo / ofresidas tengo recusado al s[eño]r oydor dotor d[o]n / Juan de la peña y salasar y por allarse su m[erce]d / solo en la r[ea]l sala se mando reserbar el pro / beydo a mi escrito de recusasion en el $\mathrm{r}[\mathrm{ea}] \mathrm{l} /$ acuerdo para quando biniese el s[eño]r oydor / Dotor d[on] Gaspar de Cuba y arçe que oy se alla / en la provincia de cuyo y porque de sus / pender el probeydo sobre la $\mathrm{d}[\mathrm{ic}]$ ha soltura / y desenbargo de bienes me es yrreparable / perjuicio y que se debieran en este caso en confor / midad de la ley Real nombrar letrados que / determinasen el d[ic]ho articulo y que la falta / de ellos no me debe ser perjudicial en aten / sion de ser noticia la seguridad de mi persona / y de asegurarse bastantem[en]te el juicio con / el abono de mis bienes y mas con las fianzas / que de uno y otro ofresco sea de servir V[uestra] s[eñori]a / y en la forma que mas aya lugar de derecho / y por la notoria falta de jueces de mandar / que en el interin que viene a esta Real / audiencia el d[ic]ho señor oydor dotor don gas / par de cuba y arçe de la provincia de / Cuyo sea suelta de la prision y desen / bargados los d[ic]hos bienes debaxo de las / fianzas que tengo ofresidas y desuso $\mathrm{o} /$ fresco mediante lo qual y mas fabora / ble $=\mathrm{a} \mathrm{V}$ [uestra] $\mathrm{s}$ [eñori]a Pido y suplico que en aten / sion de las causas sobred[ic]has se sirva de / mandar hacer como desuso pido sobre / que pido justicia y en lo necesario Ut Supra Doña Catalina de los RRios $(158,158 v)$.

A propósito de esta petición de Catalina de los Ríos es que aparece por primera vez el nombre del Gobernador de Chile, Francisco de Meneses, quien en auto fechado el día 13 de diciembre de 1664, acepta la fianza carcelera, la mantiene "presa” en su casa y lo más importante de todo, levanta el embargo de sus bienes ${ }^{23}$. El documento finaliza, en una sexta y última

${ }_{23}$ "abiendo visto / esta peticion presentada por parte de doña / Catalina de los rrios dixo que atento a q[ue] / son notorias las causas que se refieren / en este escrito y la falta de jueces para deter / minar en lo principal como en los demas / articulos que estan pendientes en la real / Audiencia y se tratan contra la susodicha / por ahora justicia mediante manda y / mando quedando la susod[ic]ha fianzas / [...] y abonadas de a seguridad de / su persona en forma de fianza carcelera / y de lo jusgado y sentenciado en la d[ic]ha / causa que refiere en este escrito en / tendera su prision dentro de quatro leguas / esta ciudad en contorno y no en mayor / distanca en el ynterin que aya copia de / jueses en la r[eal] audiencia que provean de / justicia en la d[ic]ha causa y sus articuos y lo con / tenido en 
parte, con una última aparición de Ugas, quien reitera que lo consignado es una copia fiel del original y que el objetivo de su traslado es para que conste en la documentación de Munibe, caballero de la orden de Alcántara, consejero y oidor de su majestad en la Audiencia de Lima y juez visitador del proceso contra el gobernador Meneses: "asi doi el presente en la ciu[da]d / de s[a]ntiago de Chile en beynte y tres de hen[er]o de / mill y s[eiscient]os y setenta a[ño]s / en t[esti]monio de verdad / geronimo de ugas / ess[criban] o PP[ublic]o de Cavildo y r[eal]" (163) y finaliza certificando que hace entrega del mismo, nuevamente Francisco Muñoz.

\section{Palabras finales}

Para Alejandra Araya, la Quintrala, entendida como ícono cultural, funciona como una representación "de la condición colonial en tanto situación de opresión y abuso" (2014: 198), que encubre al verdadero ícono del mal gobierno, al tirano que lleva consigo el desprestigio de la administración española de sus colonias ultramarinas ${ }^{24}$.

Sin lugar a duda, la Quintrala y Barrabás comparten la clave del descaro, ya que, si bien ambos actualizan prácticas propias de gobernadores y encomenderos, su característica principal reside en que hacen estallar los delgados límites en que esas prácticas son toleradas por la administración judicial, transformándose en escandalosas ${ }^{25}$. En definitiva, el exceso

este auto pasara ante el cap[ita]n / Joseph Albares de Toledo es[cribano] pu[blic]o de esta ciudad / y a su satisfasion y quedandose con un tan / to deste y los demas autos que hisiere entre / gara los orijinales al secretario de ca / mara desta r[ea]l audiencia para que los pon / ga en la causa principal y lo firmo dada / la fianza en la forma referida se le alza / el embargo de sus bienes" (G159-159v).

24 “¿Por qué no pensar que la elección de Catalina por sobre la de Meneses como ícono de las leyendas decimonónicas sobre el abuso colonial, no es sino una transferencia de la crítica a la tiranía, que nunca se puede hacer en forma directa sin riesgo de muerte? ¿Por qué no es el llamado "Barrabás" el objeto de nuestros desvelos ya no infantiles sino que autoritarios y dictatoriales? ¿No es Meneses acaso nuestro primer Pinochet?” (Araya 2014: 206).

${ }^{25} \mathrm{Cf}$. Albornoz, María Eugenia. "Rumores venenosos, cartas engañosas, gritos de crítica social. Los poderes (im)posibles de las voces femeninas en Chile, 1660-1750", América sin nombre $\mathrm{N}^{\circ} 15$ (2010): 79-92. 
que portan está vinculado a la ostentación que ambos parecen hacer de su dominio e impunidad en el espacio público. En ese sentido la presencia de Catalina de los Ríos, la encomendera, en el juicio del gobernador, no hace más que realzar las redes de contactos y privilegios locales que la corona española estaba tan interesada en evitar. Además, conceptualizar el actuar de Catalina de los Ríos como excepcional, no haría sino desconocer el contexto de abusos generalizado propio del período (dentro y fuera de la legislación vigente).

Vale la pena reiterar, entonces, que Geronimo de Ugas entendido como autor del cargo 133, construye un relato narrativo que se sostiene únicamente en la voz autorizada que ostenta el escribano público en la sociedad virreinal, y lo que construye narrativamente (a través de la selección de información y fragmentos de las causas judiciales a las que tiene acceso) es justamente el enfrentamiento de la "verdadera" justicia de la corona (que se pretende conseguir a través del juicio de residencia) con la élite local (las figuras de autoridad vinculadas a los miembros de las familias ricas del reino).

Por otra parte, quisiera relevar que este documento es un antecedente valiosísimo a la hora de investigar la emergencia narrativa de los relatos que tienen a Catalina de los Ríos como protagonista. Asumir que Ugas no hizo más que copiar fragmentos de las causas que se encuentran en la Audiencia no invalida dicha aseveración, ya que el hecho de copiar, y sobre todo de seleccionar, de manera explícita, fragmentos de dichos juicios para un fin nuevo (convertirlos en un cargo contra el gobernador) le da un sentido textual autónomo diferente, pero íntimamente emparentado al de las causas judiciales en las que se basa. El valor de este documento es innegable, ya que, si bien el tenor del texto es formulaico, no sólo se configuran las identidades invisibilizadas de los subalternos (y el escenario del horror y la muerte del que están escapando) sino también, en este caso, la de uno de los personajes históricos coloniales acerca del que más se ha hablado y escrito en la historia de Chile a partir de la década de 1870. Al igual que en los interrogatorios de Salcedo, estamos en presencia aquí de su voz, de la construcción ficcional de la voz de esta mujer que va a ser recreada de manera casi obsesiva por la literatura chilena. El gesto inaugural de este tipo de documentación en ese sentido es innegable. 


\section{Bibliografía}

Adorno, Rolena. (1996). "La estatua de Gonzalo Guerrero en Akumal: íconos culturales y la reactualización del pasado colonial”. Revista Iberoamericana 176-177: 905-923.

Albornoz, María Eugenia. (2010). "Rumores venenosos, cartas engañosas, gritos de crítica social. Los poderes (im)posibles de las voces femeninas en Chile, 1660-1750", América sin nombre $\mathrm{N}^{\circ}$ 15: 79-92.

Alfonso X. (1576). Las siete partidas del sabio Rey don Alonso El Nono /nuevamente glosadas por el licenciado Gregorio López, del Consejo Real de Indias de su Magestad, con su repertorio muy copioso asi del testo como de la glosa. Salamanca: Casa de Domingo de Portonarijs Urfino, Impressor de la Sacra Real Magestad.

Alone. (1954). Historia personal de la literatura chilena. Santiago: ZigZag.

Amunátegui, Miguel Luis. (1871). Precursores de la independencia de Chile. Tomo II. Santiago: Imprenta de la República.

. (1882). "Doña Catalina de los Rios de Campofrio Carvajal". El terremoto del 13 de mayo de 1647. Santiago: Rafael Jover, Editor, 38-104.

Amunátegui Solar, Domingo. (1910). Las encomiendas de indíjenas en Chile: memoria histórica presentada a la Universidad de Chile en cumplimiento del artículo 22 de la ley de 9 de Enero de 1879. Santiago: Cervantes.

Araya, Alejandra. (2014). "Azotar. El cuerpo, prácticas de dominio colonial e imaginarios del reino a la república de Chile”. Formas de control y disciplinamiento. Chile, América y Europa siglo xvi-xix. Eds. Verónica Undurraga y Rafael Gaune. Santiago: Uqbar Editores, 194-215.

Azúa, Ximena. (1995). "Las prácticas judiciales de la colonia, Historias de nuestras bisabuelas”. Tesis para optar al grado de Licenciada en Lengua y Literatura Hispánica. Facultad de Filosofía y Humanidades. Universidad de Chile. Profesora: Lucía Invernizzi Santa Cruz. Santiago.

Azúa, Ximena y Eltit, Bernardita. (2012). "Corregidor Zañartu. Autoritarismo y Linaje”. Revista de Estudios Filológicos, Facultad de Filosofía y Humanidades de la Universidad Austral de Chile. Versión impresa ISSN 0071-1713. Valdivia Chile, junio, pp. 7-23. 
Barros Arana, Diego. (1884, 1885). Historia Jeneral de Chile. Tomos III, IV y V. Santiago: Rafael Jover Editor.

Bottinelli, Alejandra. (2008). "Benjamín Vicuña Mackenna: construir un sujeto, ensayar una nación. Racismo, élites e imaginario nacional en el Chile del XIX". Tesis Universidad de Chile.

Cisternas, Natalia. (2001). "La Quintrala como construcción discursiva. Análisis al diseño historiográfico de Catalina de los Ríos Lisperguer de Benjamín Vicuña Mackenna”, Anuario de posgrado 4. Facultad de Filosofía y Humanidades, Universidad de Chile, 429-438.

Eltit, Bernardita. (2019). "Fábulas judiciales. Cruces para una propuesta metodológica”. Joaquín Trujillo y Emilia Jocelyn-Holt (eds.) Ficciones jurídicas. Derecho y literatura en Chile. Santiago: Rubicón, pp. 103128.

(2017). "Fábulas judiciales. Origen y actualizaciones de la biografía criminal del ícono cultural Quintrala (siglos XVII y XIX)". Tesis para optar al grado de Doctora en Literatura. Universidad de Chile.

Garabano, Sandra. (2009). "Una herencia monstruosa: mestizaje y modernización en Chile”, Revista Iberoamericana 227: 349-362.

González Undurraga, Carolina. (2014). Esclavos y esclavas demandando justicia. Chile, 1740-1823. Documentación judicial por carta de libertad y papel de venta. Santiago: Universitaria.

Grau, Olga. (2002). "Benjamín Vicuña Mackenna y la Quintrala”. Pierre Bourdieu y la sociología crítica. Resistir la dominación. Cuadernos Sociológicos. Santiago: Editorial ARCIS, 127-156.

Guerra Cunningham, Lucía. (2002). "Historia y representación: el caso de la Quintrala”. Morada de la palabra Vol 1. (William Mejías López ed.). Puerto Rico: Editorial de la Universidad de Puerto Rico, 804-810.

Jocelyn Holt, Alfredo. (2001). "Nuestra yo la peor de todas: la Quintrala”. Actas tercer tribunal de los derechos de las mujeres chilenas. Santiago: Fundación Instituto de la mujer, 19-31.

Lozano, Pedro. (1874). Conquista del Paraguay, Río de la Plata y Tucumán. Tomo tercero. Buenos Aires: Imprenta popular.

Martínez Baeza, Sergio. (1999). "Jueces y tribunales de Residencia en Chile”. Revista Chilena de Historia del Derecho 18: 239-244.

Maturana, Víctor. (1904). Historia de los Agustinos en Chile Tomo I. Santiago: Imp. Valparaíso de Federico T. Lathrop. 
Roggero, Jorge. (2015). Derecho y literatura. textos y contextos. Buenos Aires: Eudeba.

Sarabia, Rosa. (2000). "Doña Catalina de los Ríos Lisperguer y la construcción del monstruo Quintrala”. Anales de literatura chilena 1: 35-52. Smietniansky, Silvina. (2007). "El juicio de residencia como ritual político en la colonia (gobernación de Tucumán siglo xviii)”. Memoria Americana 15: 71-101.

Solórzano Pereira, Juan. (1648). Política indiana. Madrid: Diego Díaz de la Carrera.

Valenzuela, Jaime. (2013). Las liturgias del poder. Celebraciones públicas y estrategias persuasivas en Chile colonial (1609-1709). Santiago: LOM.

Vicuña Mackenna, Benjamín. (1877). "Doña Catalina de los Ríos ('La Quintrala')”. El Ferrocarril. [Santiago de Chile]. 21 enero: 1. . (1877). Los Lisperguer y la Quintrala (Doña Catalina de los Ríos). Episodio histórico-social. Con numerosos documentos inéditos por B. Vicuña Mackenna. Segunda edicion estensamente aumentada $i$ correjida. Valparaíso: Imprenta del Mercurio. . (1884). "El último de los cuarenta asesinatos de Doña Catalina de los Ríos”. Revista de Artes y Letras I, 46-70. 